\title{
The Effect of Autochthonous Starter Culture, Sugars and Temperature on the Fermentation of Slavonian Kulen
}

\author{
Krešimir Mastanjevićc ${ }^{*}$, Dragan Kovačević ${ }^{1}$ Jadranka Frece ${ }^{2}, K_{\text {Ksenija Markov }}^{2}$ \\ and Jelka Pleadin ${ }^{3}$ \\ ${ }^{1}$ University of J. J. Strossmayer in Osijek, Faculty of Food Technology Osijek, \\ Department of Food Technology, Kuhačeva 20, HR-31000 Osijek, Croatia \\ ${ }^{2}$ University of Zagreb, Faculty of Food Technology and Biotechnology, Laboratory for General \\ Microbiology and Food Microbiology, Pierottijeva 6, HR-10000 Zagreb, Croatia \\ ${ }^{3}$ Croatian Veterinary Institute, Laboratory for Analytical Chemistry, Savska Cesta 143, \\ HR-10000 Zagreb, Croatia
}

Received: March 7, 2016

Accepted: October 12, 2016

\begin{abstract}
Summary
In this study, the effect of an isolated and well-characterised autochthonous starter culture, glucose and maltodextrin $(w=0.8 \%)$ and temperatures of 12 and $20^{\circ} \mathrm{C}$ on fermentation and quality of Slavonian kulen produced using the traditional technology and recipe were investigated. Physicochemical and microbiological analyses were carried out after 20 days of fermentation. Upon the completion of the production process (90 days), a sensory analysis was carried out. Furthermore, $\mathrm{pH}$ value was continuously measured throughout the twenty-day fermentation period. The addition of an autochthonous starter culture and sugars and different fermentation temperatures significantly $(p<0.05)$ affected the instrumental colour and texture parameters of the Slavonian kulen. The fermentation was most intense in the samples with added autochthonous starter culture and $0.8 \%$ glucose, and fermented at $20^{\circ} \mathrm{C}$. Microbiological analysis showed that samples with added autochthonous starter culture and fermented at higher temperature contained a higher number of lactic acid bacteria and coagulase-negative staphylococci and were safe. Sensory evaluation confirmed the outcomes of physicochemical and microbiological analyses and showed differences among samples fermented at two different temperatures and with added glucose or maltodextrin and an autochthonous starter culture.
\end{abstract}

Key words: Slavonian kulen, autochthonous starter culture, sugars, fermentation temperature, physicochemical, microbiological and sensory properties

\section{Introduction}

Slavonian kulen is the most representative traditional Croatian fermented pork sausage produced in rural settings using a traditional technology and industrial settings according to a modified recipe (which includes the addition of commercial bacterial starter cultures, nitrate and nitrite salts and isoascorbate). This sausage is traditionally made from the first and second class pork previ- ously cleaned of connective tissue, damaged parts, blood vessels and fatback, spiked with salt, red hot and sweet paprika powder and garlic, the stuffing ultimately being filled into the pork appendix (intestinum caecum). Once the stuffing is conditioned, the sausage is smoked, fermented, dried and ripened for several months $(1,2)$. Due to the various technological processes used for the sausage production, including hurdle technology, the activity of technological 
microflora (especially vivid during the fermentation process) and long-term maturation, complex microbiological, physicochemical and biochemical processes take place resulting in the change of fundamental building materials (fats, proteins and carbohydrates), water loss and increase in dry mass (3).

Nowadays, bacterial starter cultures are widely used in the industrial production of fermented sausages to overcome the fermentation problems, reduce the variability of the product quality, limit the growth of spoilage bacteria by accelerating fermentation, and improve the sensory properties of fermented meat products (4). Fermentation is the crucial phase of dry sausage curing, since in this stage major physical, biochemical and microbiological transformations occur $(5,6)$. Meat conservation by fermentation is characterised by several factors: $\mathrm{pH}$ decrease, changes in the initial count of microflora, reduction of nitrates first to nitrites and later on to nitric oxide, formation of nitrosomyoglobin, solubilisation and gelification of myofibrillar and sarcoplasmic proteins, proteolytic, lipolytic and oxidative changes, and dehydration (7). The process is also characterised by the increase in the number of lactic acid bacteria (LAB) from $10^{3}-10^{5}$ to $10^{6}-10^{9} \mathrm{CFU} / \mathrm{g}$, as well as by glycolytic sugar degradation and the increase in lactic acid concentration. The increase in lactic acid concentration causes a $\mathrm{pH}$ decrease from the initial 5.7 to 5.5 in slow-fermented sausages and to 4.6 (sometimes even 4.2$)$ in fast-fermented sausages $(8,9)$. Bacterial starter cultures used for meat fermentation are the preparations of viable bacteria that exhibit a desired metabolic activity, primarily acidification, and are responsible for the development of aroma during meat fermentation (10). They are composed of the strains of lactic acid bacteria primarily belonging to the Lactobacillus or Pediococcus genus, as well as of coagulase-negative staphylococci (CNS) and the members of the Micrococcaceae genus (4).

Fermentation is most intense during the first few hours, when the temperature rises up to the values optimal for LAB growth. This can take from $12 \mathrm{~h}$ to 7 days or even longer, depending on the product type, additives, production technology and production environment, i.e. temperature and relative air humidity. Higher temperatures and higher relative air humidity $(\mathrm{RH})$ speed up the fermentation process and decrease the $\mathrm{pH}$ value. Depending on the bacterial strains, fermentation can be carried out at temperatures ranging from $18-24{ }^{\circ} \mathrm{C}$ or higher for 1-2 days, or at lower temperatures $\left(10-12{ }^{\circ} \mathrm{C}\right)$ for over a week. However, in some cases fermentation can last for over a week even if taking place at higher fermentation temperatures (e.g. in the production of Greek and some Italian sausages) $(11,12)$.

Since the glucose content in meat is too low or much too variable, and in order to provide sufficient quantities different carbohydrates, like glucose, sucrose, lactose, maltodextrin, corn syrup, starch and sorbitol are added to the fermented sausage stuffing. These carbohydrates enhance the growth of technological microflora, primarily LAB (13). The most common substrate used in this type of fermentation is glucose, consumed during the LAB exponential growth phase.

Fermentation temperature, mass fraction and the type of added sugar directly affect the $\mathrm{pH}$ decrease rate.
Low $\mathrm{pH}$ inhibits the growth of pathogens and spoilage bacteria, while glucose and salt increase the osmotic pressure, which favours the growth of autochthonous technological bacteria. Sugars, mostly glucose, facilitate dry sausage fermentation, since they serve as a substrate for the lactic acid production and contribute to the specific aroma development. Up to $2 \%$ (on average $0.3-0.8 \%$ ) of sugars are added into the fermented sausage stuffing to ensure the $\mathrm{pH}$ decrease from the initial 5.8-6.0 to $4.8-5.4$ (14).

Inoculation of the sausage stuffing with a starter culture composed of the selected LAB (i.e. homofermentative Lactobacilli and/or Pediococci) and non-pathogenic CNS and/or Kocuria improves the quality and safety of the final product and contributes to the standardisation of the production process (13-16).

The goal of this study is to evaluate the impact of an isolated and well-characterised autochthonous starter culture, glucose and maltodextrin $(w=0.8 \%)$ and two fermentation temperatures $\left(12\right.$ and $\left.20^{\circ} \mathrm{C}\right)$ on the fermentation process and quality of the Slavonian kulen.

\section{Materials and Methods}

\section{Microorganisms}

Starter cultures, bacterial strains Lactobacillus plantarum $1 \mathrm{~K}$ and Staphylococcus carnosus $4 \mathrm{~K} 1$, characterised as functional (1,7-12), are originally isolated from the traditional Croatian fermented sausages. These strains are utilised in an industrial sausage production. Bacterial strains were acquired from the collection of microorganisms stored in the Laboratory for General Microbiology and Food Microbiology, Department of Biochemical Engineering, Faculty of Food Technology and Biotechnology, University of Zagreb, Zagreb, Croatia. Lactobacillus plantarum $1 \mathrm{~K}$ and Staphylococcus carnosus $4 \mathrm{~K} 1$ were kept at $-70{ }^{\circ} \mathrm{C}$ in de Man-Rogosa-Sharpe (MRS) broth (Difco ${ }^{\mathrm{TM}}$, Detroit, MI, USA) and nutrition broth (Biolife, Milano, Italy) with 30 $\%$ (by volume) glycerol. The strains were activated in the above mentioned broths and maintained at $4{ }^{\circ} \mathrm{C}$ until propagation.

\section{Preparation of wet biomass}

The LAB were grown in the MRS broth at $30^{\circ} \mathrm{C}$ for 48 $\mathrm{h}$, while the Staphylococcus was grown in the nutrition broth at $37{ }^{\circ} \mathrm{C}$ for $48 \mathrm{~h}$. Bacterial cells were harvested under aseptic conditions as follows: first they were centrifuged (at $6000 \times g$ for $10 \mathrm{~min}$ ) at room temperature, then washed three times in salt water $(0.5 \%)$ and finally resuspended in a sterile salt water. A standard dilution method after a 48-hour incubation at $37{ }^{\circ} \mathrm{C}$ in MRS and nutrition agar was used to assess the total viable count (TVC). The final counts of bacterial cells were: $10^{11}$ L. plantarum $1 \mathrm{~K}$ viable bacterial cells per $\mathrm{g}$ of wet biomass, and $10^{7}$ S. carnosus $4 \mathrm{~K} 1$ viable bacterial cells per $\mathrm{g}$ of wet biomass (17).

\section{Sample preparation}

Slavonian kulen was produced in a pilot plant (Faculty of Food Technology, Osijek, Croatia) intended for dry sausage production, equipped with a programmable au- 
tomated ripening chamber. The Slavonian kulen stuffing was prepared according to the traditional recipe: pork meat (of the first and second class, $91.8 \%$ ), pork fatback ( 5 $\%)$, garlic $(0.2 \%)$, red hot paprika powder $(0.4 \%)$, sweet red paprika powder $(0.6 \%)$ and salt $(2 \%)$. The meat was ground through a grinding plate with $8-\mathrm{mm}$ diameter holes, while the pork fatback was ground through a grinding plate with 6-mm holes. The batches with added autochthonous starter culture were inoculated with L. plantarum $1 \mathrm{~K}$ in the final concentration of about $10^{6}$ cells per $\mathrm{g}$ and $S$. carnosus $4 \mathrm{~K} 1$ in the final concentration of about $10^{3}$ cells per $\mathrm{g}$. To these samples, $0.8 \%$ of glucose or maltodextrin (both from Sigma-Aldrich, Taufkirchen, Germany) were added, as well.

The Slavonian kulen stuffing was stuffed into the pig appendix. After stuffing, the raw samples were cold-smoked using a dry hardwood (hornbeam, beech and its sawdust) every few days (for 3-4 h) for two weeks. A 20-day fermentation process was carried out at two different temperatures (Table 1) and relative humidity $(\mathrm{RH})$ of 80 to $90 \%$. After smoking and fermentation, all samples were left to rest in the ripening chamber at the temperature from 14 to $17{ }^{\circ} \mathrm{C}$ and $\mathrm{RH}$ from 70 to $80 \%$. The entire technological process running under the processing conditions detailed above lasted for 90 days. A total of 15 samples of raw Slavonian kulen were divided into five batches (Table 1).

Table 1. Samples of the Slavonian kulen prepared according to the traditional recipe with the addition of glucose or maltodextrin and fermented with autochthonous starter culture at different temperatures

\begin{tabular}{ccc}
\hline Batch & $t /{ }^{\circ} \mathrm{C}$ & $w$ (sugar) $=0.8 \%$ \\
\hline B1 & 20 & control \\
B2 & 12 & glucose \\
B3 & 20 & glucose \\
B4 & 12 & maltodextrin \\
B5 & 20 & maltodextrin \\
\hline
\end{tabular}

Control=without sugar and autochthonous starter culture; $N=3$

\section{Physicochemical analysis}

The water content was determined gravimetrically (18) at $103{ }^{\circ} \mathrm{C}$ (model Epsa 2000; Bari, Velika Gorica, Croatia). The total protein content was determined by the Kjeldahl method (19) using a Unit 8 Basic digestion block (Foss, Hillerød, Denmark) and a Kjeltec 8400 automated distillation and titration device (Foss). The total fat content was determined by the Soxhlet method (20). The sample was submitted to digestion in an acidic environment followed by petroleum ether-induced fat extraction using a Soxtherm 2000 automated device (C. Gerhardt Gmbh \& CO. KG, Königswinter, Germany). Collagen content was determined by the spectrophotometric analysis of hydroxyproline (21) using a spectrophotometer model DR/4000U (Hach, Düsseldorf, Germany). Titration method was applied in order to determine the salt content (22) using $2 \mathrm{~g}$ of each sample. Samples were homogenised with sand and $3 \mathrm{~mL}$ of water and the content was transferred into a $100-\mathrm{mL}$ volumetric flask, stirred and placed into a water bath at $100{ }^{\circ} \mathrm{C}$ for $15 \mathrm{~min}$. After cooling, the flask was filled with water up to the mark and filtered. An aliquot $(25 \mathrm{~mL})$ of the filtrate was transferred into an Erlenmeyer flask containing a few drops of $\mathrm{K}_{2} \mathrm{CrO}_{4}$ as an indicator (62 g per $100 \mathrm{~mL}$ of water) and titrated with $0.1 \mathrm{M}$ $\mathrm{AgNO}_{3}$ until a persistent reddish colour was obtained. The volume and concentration of the titration reagent were used to calculate the salt content. A homogenate diluted with distilled water $(1: 10)$ was used for $\mathrm{pH}$ determination with $\mathrm{pH} / \mathrm{Ion} 510$ Bench $\mathrm{pH} / \mathrm{Ion} / \mathrm{mV}$ Meter (Eutech Instruments Pte Ltd/ Oakton Instruments, Vernon Hills, IL, USA). The water activity $\left(a_{\mathrm{w}}\right)$ was determined at room temperature $\left((20 \pm 2){ }^{\circ} \mathrm{C}\right)$ using a Rotronic Hygrolab 3 (Rotronic AG, Bassersdorf, Switzerland), according to the manufacturer's instructions. Analytical grade chemicals were used for all analyses of physicochemical parameters. For each batch, analyses were done in triplicate.

\section{Texture profile analysis}

Texture profile analysis was performed at room temperature with a Universal TA.XT2i SMS Stable Micro Systems Texture Analyser (Stable Microsystems Ltd., Godalming, UK) equipped with a P/75 cylindrical probe. This involved cutting of samples into $1.5-\mathrm{cm}$ thick slices, subsequently compressed twice to $60 \%$ of their original thickness. Force-time curves were obtained at the crosshead speed of $5 \mathrm{~mm} / \mathrm{s}$ and the equal recording speed. Determined parameters involved (23): hardness, i.e. the maximum force required to compress the sample, springiness, i.e. the ability of a sample to recover its original form once the deforming force has ceased, cohesiveness, i.e. the extent to which a sample can be deformed prior to rupture, and chewiness, i.e. the effort to masticate the sample before swallowing, calculated by multiplying hardness by cohesiveness and springiness. Seven measurements were taken for each sample of the five batches.

\section{Determination of instrumental colour}

HunterLab Mini Scan XE (A60-1010-615 model colourimeter, HunterLab, Reston, VA, USA) was used to determine sample colour (CIE L*a*b*). For each measurement, a black standard (light trap) and the standard white ceramic plate $\left(L^{*}=93.01, a^{*}=-1.11\right.$, and $\left.b^{*}=1.30\right)$ were applied to standardised the instrument. The Hunter $L^{*}, a^{*}$ and $b^{*}$ values correspond to lightness (0 (black) to 100 (white)), greenness $\left(-a^{*}\right)$ or redness $\left(+a^{*}\right)$, and blueness $\left(-b^{*}\right)$ or yellowness $\left(+b^{*}\right)$, respectively. Colour measurements were performed at room temperature $\left((20 \pm 2){ }^{\circ} \mathrm{C}\right)$. For each sample of the five batches, ten measurements were made.

\section{Microbiological analysis}

The determination of microbial population in Slavonian kulen samples employed classical microbiological analyses (Table 2; 24-29). The isolation of microbial populations was carried out according to the microbiological criteria for food (30) and included the isolation of Enterobacteriaceae, Staphylococcus aureus and sulphite-reducing Clostridia, Salmonella sp. and Listeria monocytogenes. 
Table 2. Classical microbiological and biochemical (API) methods used for the isolation and identification of microbial population in Slavonian kulen

\begin{tabular}{|c|c|c|c|c|c|}
\hline \multirow{2}{*}{ Microorganism } & \multirow{2}{*}{ Method } & \multirow{2}{*}{$\begin{array}{l}\text { Nutrient } \\
\text { medium }\end{array}$} & \multicolumn{2}{|c|}{ Incubation conditions } & \multirow{2}{*}{ API test } \\
\hline & & & $t /{ }^{\circ} \mathrm{C}$ & Time/h & \\
\hline Salmonella sp. & HRN EN ISO 6579:2003/A1:2008 (24) & $\begin{array}{l}\text { RP-broth, } \\
\text { XLD }\end{array}$ & 37 & $24-48$ & API 20 E V4.1 \\
\hline Enterobacteriaceae & HRN ISO 5552:1999 (25) & VRBG & 37 & 24 & API 20 E V4.1 \\
\hline Staphylococcus aureus & HRN EN ISO 6888-1:2004 (26) & $\mathrm{BP}$ & 37 & 48 & API Staph V4.1 \\
\hline Sulphite-reducing clostridia & HRN ISO 15213:2004 (27) & Sulphite agar & 37 & 72 & - \\
\hline Listeria monocytogenes & HRN EN ISO 11290-1:1999/A1:2008 (28) & $\begin{array}{l}\text { Fraser broth } \\
\text { Palcam agar }\end{array}$ & 37 & 24 & API Listeria V1.2 \\
\hline Lactic acid bacteria & HRN ISO 13721:1999 (29) & MRS agar & 30 & $48-72$ & $\begin{array}{l}\text { API } 50 \text { CHL V5.1 } \\
\text { API } 20 \text { STREP V7.0 }\end{array}$ \\
\hline
\end{tabular}

After the casing was aseptically removed and discarded, $10 \mathrm{~g}$ of a sample were homogenised in $90 \mathrm{~mL}$ of sterile $0.5 \%$ saline solution and serially diluted before plating on selective nutrient media (Biolife) (Table 2; 24 29). The incubation took place under aerobic conditions at $37^{\circ} \mathrm{C}$ for $48 \mathrm{~h}$. Microbial growth (CFU/g) was determined using the traditional plate counting.

\section{Isolation and identification of microbial population}

The identity and viability of the applied autochthonous starter cultures and natural microbial population in Slavonian kulen samples were determined using API $50 \mathrm{CH}$ and API Staph identification kits (bioMérieux, Marcy l'Etoile, France). Colonies randomly taken from the MRS (150 colonies) and the Baird Parker agar (100 colonies) (26), descriptive of five samples, were determined using identification kits and then authenticated using a Microflex LT $^{\mathrm{TM}}$ matrix-assisted laser desorption-ionisation time-of-flight mass spectrometer (MALDI-TOF MS; Bruker Daltonik, Bremen, Germany) (31). For identification purposes, the peaks from the generated mass spectra were compared to the reference spectra of the integrated database using the MALDI Biotyper software (Bruker Daltonik).

\section{Sensory analysis}

The final Slavonian kulen samples from all five batches (obtained after 90 days) were subjected to a quantitative descriptive analysis. The analysis was performed by a panel of seven (three male and four female) trained experts according to the ISO standard (32). The panellists had completed three preliminary training sessions in order to familiarise themselves with the involved samples. Twelve attributes were examined and rated on a 5-point scale: 1 standing for poorly perceived or absent and 5 standing for intensely perceived. During these three training sessions, an agreement on the descriptors to be targeted by the analysis was made. This agreement included: two external attributes (appearance and hardness), two attributes describing the slice (colour uniformity and sliceability), five attributes describing the experience during mastication (flavour intensity, juiciness, smokiness, acidic taste and saltiness) and three attributes describing the product smell (spicy odour, lactic acid odour and mouldy odour). The appearance of Slavonian kulen samples was assessed visually, while the hardness was assessed by palpation. The sliceability as a textural property was assessed visually (to see whether any crumbling is present or whether the pieces of the sausage are falling out). A three-digit code was used for coding of sausage samples. Samples were served cut into approx. $0.4 \mathrm{~cm}$ thick slices. In order to cleanse the palate water was offered between the analyses.

\section{Statistical analysis}

The results are shown as mean value \pm standard deviation. Experimental output was processed using the analysis of variance (ANOVA) and the Fisher's least significant difference (LSD), with the significance defined at the level of probability of $95 \%(p<0.05)$. Statistical analysis was carried out using the Statistica v. 12.7 software (StatSoft Inc. Tulsa, OK, USA).

\section{Results and Discussion}

Physicochemical analysis of the meat and fatback (Table 3) used for Slavonian kulen stuffing showed the mass fraction of the basic building blocks (fat, moisture, proteins and collagen) to be in accordance with the literature data on fresh pork meat and fatback analysed $24 \mathrm{~h}$ post mortem. The water activity and $\mathrm{pH}$ values are also in agreement with the data obtained by the previous research on similar samples (2). A drop in $\mathrm{pH}$ values measured 24 h post mortem down to below 6 should be observed in meat used for dry sausages, but also for other meat products. This indicates the normal course of post mortal glycolysis, lactic acid production and $\mathrm{pH}$ value dropdown.

In Slavonian kulen, changes in mass fraction of individual building blocks and water activity $\left(a_{\mathrm{w}}\right)$ cease after 20 days (Table 4 ), mostly due to drying. The obtained $a_{\mathrm{w}}$ of 0.91 was lower than 0.946 and 0.93 reported for a Spanish sausage fermented under similar conditions, but using a different commercial starter culture $(5,33)$. On the other hand, other authors reported the $a_{\mathrm{w}}$ of 0.88 on day 21 of fermentation and drying of chorizo with added $1 \%$ of glucose and Lactobacillus sakei K29 and whose fermentation and drying took place under similar conditions of temperature and relative humidity (34). 
Table 3. Basic chemical composition, water activity $\left(a_{\mathrm{w}}\right)$ and $\mathrm{pH}$ of pork fatback, meat and stuffing used for the production of Slavonian kulen

\begin{tabular}{lcccccc}
\hline & $w$ (fat) $/ \%$ & $w$ (moisture) $/ \%$ & $w$ (protein) $/ \%$ & $w$ (collagen) $/ \%$ & $a_{\mathrm{w}}$ & $\mathrm{pH}$ \\
\hline Backfat & $(74.00 \pm 0.06)^{\mathrm{a}}$ & $(19.93 \pm 0.03)^{\mathrm{c}}$ & $(7.3 \pm 0.4)^{\mathrm{c}}$ & $(2.7 \pm 0.1)^{\mathrm{a}}$ & $(0.96 \pm 0.01)^{\mathrm{a}}$ & $(6.63 \pm 0.01)^{\mathrm{a}}$ \\
Meat & $(9.00 \pm 0.03)^{\mathrm{c}}$ & $(70.67 \pm 0.08)^{\mathrm{a}}$ & $(19.8 \pm 0.4)^{\mathrm{a}}$ & $(1.4 \pm 0.5)^{\mathrm{b}}$ & $(0.95 \pm 0.01)^{\mathrm{a}}$ & $(5.62 \pm 0.01)^{\mathrm{b}}$ \\
Raw stuffing & $(12.37 \pm 0.04)^{\mathrm{b}}$ & $(64.3 \pm 0.1)^{\mathrm{b}}$ & $(18.84 \pm 0.07)^{\mathrm{b}}$ & $(1.20 \pm 0.03)^{\mathrm{b}}$ & $(0.94 \pm 0.01)^{\mathrm{a}}$ & $(5.51 \pm 0.01)^{\mathrm{c}}$ \\
\hline
\end{tabular}

Values are mean \pm standard deviation (S.D.), $N=3$. Values in the same column marked with different letters in superscript are significantly different $(\mathrm{p}<0.05)$

Table 4. Basic chemical composition, salt content and water activity $\left(a_{\mathrm{w}}\right)$ of the Slavonian kulen samples, determined after 20 days of fermentation

\begin{tabular}{ccccccc}
\hline Batch & $w$ (fat)/\% & $w$ (moisture) $/ \%$ & $w$ (protein)/\% & $w$ (collagen)/\% & $a_{\mathrm{w}}$ & $w($ salt $) / \%$ \\
\hline B1 & $(17.40 \pm 0.08)^{\mathrm{a}}$ & $(54.7 \pm 0.4)^{\mathrm{b}}$ & $(25.1 \pm 0.2)^{\mathrm{c}}$ & $(1.06 \pm 0.03)^{\mathrm{b}}$ & $(0.91 \pm 0.01)^{\mathrm{b}}$ & $(2.73 \pm 0.09)^{\mathrm{b}}$ \\
B2 & $(17.3 \pm 0.2)^{\mathrm{b}}$ & $(53.9 \pm 0.2)^{\mathrm{c}}$ & $(25.2 \pm 0.3)^{\mathrm{b}}$ & $(1.21 \pm 0.07)^{\mathrm{ab}}$ & $(0.91 \pm 0.01)^{\mathrm{b}}$ & $(2.67 \pm 0.08)^{\mathrm{c}}$ \\
B3 & $(17.0 \pm 0.1)^{\mathrm{c}}$ & $(52.61 \pm 0.07)^{\mathrm{e}}$ & $(25.6 \pm 0.2)^{\mathrm{a}}$ & $(1.2 \pm 0.1)^{\mathrm{a}}$ & $(0.91 \pm 0.01)^{\mathrm{b}}$ & $(2.72 \pm 0.09)^{\mathrm{b}}$ \\
B4 & $(16.0 \pm 0.2)^{\mathrm{e}}$ & $(55.18 \pm 0.06)^{\mathrm{a}}$ & $(24.9 \pm 0.1)^{\mathrm{d}}$ & $(1.23 \pm 0.05)^{\mathrm{a}}$ & $(0.91 \pm 0.01)^{\mathrm{b}}$ & $(2.67 \pm 0.06)^{\mathrm{c}}$ \\
B5 & $(16.3 \pm 0.4)^{\mathrm{d}}$ & $(53.11 \pm 0.03)^{\mathrm{d}}$ & $(25.1 \pm 0.2)^{\mathrm{c}}$ & $(1.3 \pm 0.3)^{\mathrm{a}}$ & $(0.92 \pm 0.01)^{\mathrm{a}}$ & $(2.78 \pm 0.08)^{\mathrm{a}}$ \\
\hline
\end{tabular}

Values are mean \pm S.D., $N=3$. Values in the same column marked with different letters in superscript are significantly different $(p<0.05)$

Temperature and $\mathrm{RH}$ in the automated chamber during the production of all five Slavonian kulen batches are presented in Figs. 1 and 2. The RH and temperature were within the limits specified for Slavonian kulen production stages (Table 1).

Mass loss determined in all five Slavonian kulen batches is presented in Fig. 3. It is far more substantial in the samples fermented at a higher temperature $\left(20^{\circ} \mathrm{C}\right)$ in the presence of sugars and an autochthonous starter culture, which explains lower moisture contents in these samples $(33,34)$.

During the fermentation phase, the water content in batch B3 decreased from the initial $64.3 \%$ to the lowest $52.6 \%$. The moisture content was significantly affected by the treatments $(\mathrm{p}<0.05)$ (Table 4$)$. Samples fermented at higher temperature had lower moisture contents regardless of the addition of sugars and autochthonous starter

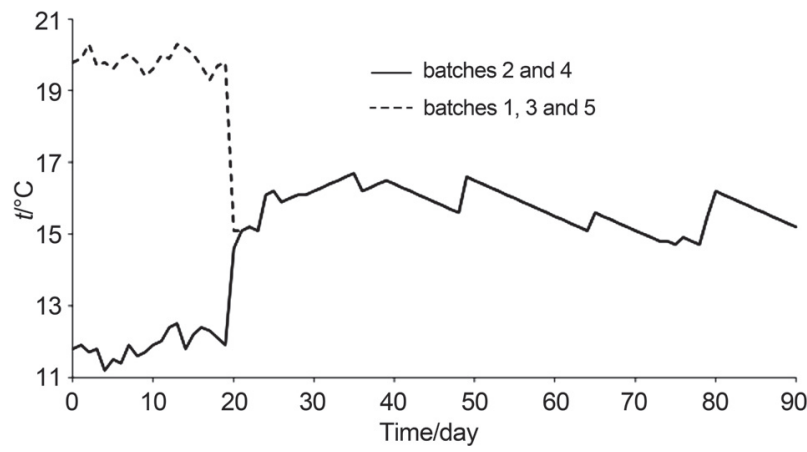

Fig. 1. Temperature regime during the production of Slavonian kulen samples: batch 1: without sugar and with autochthonous starter culture, fermented at $20^{\circ} \mathrm{C}$; batch 2 : with $0.8 \%$ glucose and autochthonous starter culture, fermented at $12{ }^{\circ} \mathrm{C}$; batch 3 : with $0.8 \%$ glucose and autochthonous starter culture, fermented at $20{ }^{\circ} \mathrm{C}$; batch 4 : with $0.8 \%$ maltodextrin and autochthonous starter culture, fermented at $12{ }^{\circ} \mathrm{C}$; batch 5 : with $0.8 \%$ maltodextrin and autochthonous starter culture, fermented at $20^{\circ} \mathrm{C}$ culture. Other studies $(33,34)$ have reported a lower moisture content $(47.53 \%)$ in a Spanish dry sausage fermented using a commercial starter culture (Lactobacillus sakei, Staphylococcus carnosus and Staphylococcus xylosus) at $15{ }^{\circ} \mathrm{C}$ and relative humidity of $80 \%$. In another study (5), a higher moisture content was reported $(56.63 \%)$ in the Spanish salchichon fermented using a commercial starter culture (Pediococcus pentosaceus and Micrococcus varian) and supplemented with $0.45 \%$ sugar (dextrose, lactose and maltodextrin). Moisture content and $a_{\mathrm{w}}$ variations may be related to the differences in the used microorganisms, the mass fraction and the type of added sugar, and the larger diameter of the Slavonian kulen casing (around $100 \mathrm{~mm})$ than that of the Spanish sausage $(60 \mathrm{~mm})$. The salt mass fraction increased from the initial $2 \%$ in raw stuffing to the average value of $2.7 \%$ after 20 days of processing, which complies with the results of similar research in the field (35) (Table 4).

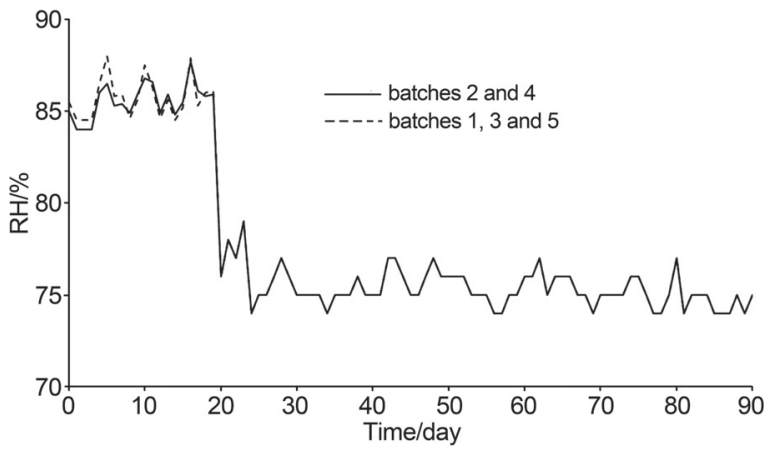

Fig. 2. Relative humidity ( $\mathrm{RH})$ during the production of Slavonian kulen samples: batch 1: without sugar and with autochthonous starter culture, fermented at $20^{\circ} \mathrm{C}$; batch 2 : with $0.8 \%$ glucose and autochthonous starter culture, fermented at $12{ }^{\circ} \mathrm{C}$; batch 3 : with $0.8 \%$ glucose and autochthonous starter culture, fermented at $20{ }^{\circ} \mathrm{C}$; batch 4 : with $0.8 \%$ maltodextrin and autochthonous starter culture, fermented at $12{ }^{\circ} \mathrm{C}$; batch 5 : with $0.8 \%$ maltodextrin and autochthonous starter culture, fermented at $20^{\circ} \mathrm{C}$ 


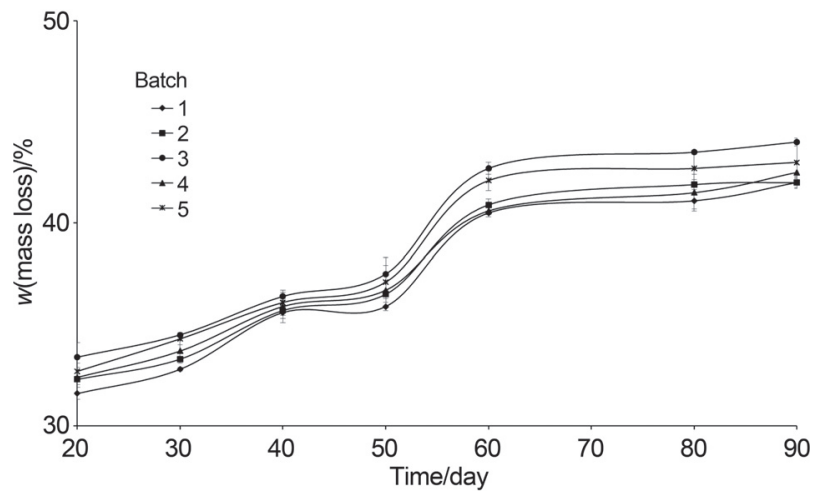

Fig. 3. Mass losses during the production of Slavonian kulen samples: batch 1: without sugar and with autochthonous starter culture, fermented at $20{ }^{\circ} \mathrm{C}$; batch 2 : with $0.8 \%$ glucose and autochthonous starter culture, fermented at $12{ }^{\circ} \mathrm{C}$; batch 3 : with $0.8 \%$ glucose and autochthonous starter culture, fermented at $20{ }^{\circ} \mathrm{C}$; batch 4 : with $0.8 \%$ maltodextrin and autochthonous starter culture, fermented at $12{ }^{\circ} \mathrm{C}$; batch 5 : with $0.8 \%$ maltodextrin and autochthonous starter culture, fermented at $20^{\circ} \mathrm{C}$

Fermentation of dry sausages is usually monitored through changes in $\mathrm{pH}$ values (36-38). Changes in the $\mathrm{pH}$ values during 20 days of processing in all five batches of the Slavonian kulen are presented in Fig. 4. The results show that in the samples of Slavonian kulen fermented at $20{ }^{\circ} \mathrm{C}$, a substantial decrease in the $\mathrm{pH}$ value was seen after 5 days, while in the samples fermented at $12{ }^{\circ} \mathrm{C}$ such a decrease was noticed after 7 days. This drop was more intense in the samples fermented at $20{ }^{\circ} \mathrm{C}$ and supplemented with an autochthonous starter culture and $0.8 \%$ glucose (batch B3), whose $\mathrm{pH}$ dropped from the initial 5.55 to 4.42 after 18 days of fermentation (39) (Fig. 4). The Slavonian kulen fermentation is significantly different from the fermentation of similar Spanish sausages (chorizo). This difference is characterised by a slower $\mathrm{pH}$ drop seen in all samples under this study. The lowest $\mathrm{pH}$ value of 4.42 ,

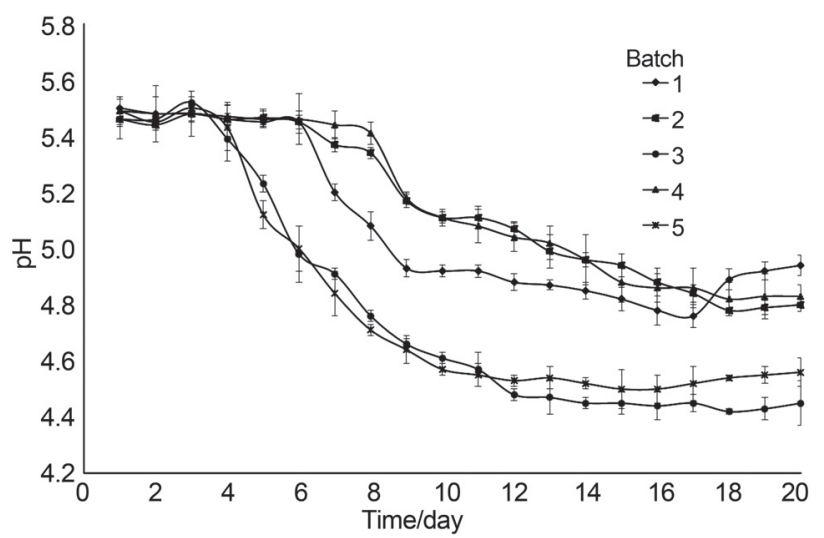

Fig. 4. Changes in $\mathrm{pH}$ values during 20 days of fermentation of Slavonian kulen samples: batch 1: without sugar and with autochthonous starter culture, fermented at $20{ }^{\circ} \mathrm{C}$; batch 2: with $0.8 \%$ glucose and autochthonous starter culture, fermented at $12{ }^{\circ} \mathrm{C}$; batch 3: with $0.8 \%$ glucose and autochthonous starter culture, fermented at $20^{\circ} \mathrm{C}$; batch 4 : with $0.8 \%$ maltodextrin and autochthonous starter culture, fermented at $12{ }^{\circ} \mathrm{C}$; batch 5 : with $0.8 \%$ maltodextrin and autochthonous starter culture, fermented at $20{ }^{\circ} \mathrm{C}$ registered in this study in batch B3, was seen on the fermentation day 17, while in the chorizo samples the lowest $\mathrm{pH}$ was reached on the ripening day 7 under similar fermentation conditions (34).

As reported by other authors (33), the $\mathrm{pH}$ of the Spanish salchichon fermented and dried for 20 days using Lactobacillus sakei, Staphylococcus carnosus and Staphylococcus $x$ ylosus at $15{ }^{\circ} \mathrm{C}$ and $\mathrm{RH}=80 \%$, equalled to 4.7. Another study (5) reported a similar result $(\mathrm{pH}=4.87)$ for a Spanish dry sausage fermented (for 3 days at $25^{\circ} \mathrm{C}$ and 90 $\% \mathrm{RH}$ ) using Pediococcus pentosaceus and Micrococcus varian and subsequently dried for 2 weeks $\left((15 \pm 18){ }^{\circ} \mathrm{C}, \mathrm{RH}=\right.$ $75-80 \%)$.

The decrease in the $\mathrm{pH}$ value comes as a consequence of the presence of lactic acid emerging due to the activity of technological microflora (LAB and CNS) and glycolysis, i.e. the transformation of sugar into lactic acid (40).

CIE L*a* $b^{*}$ values of the Slavonian kulen samples are shown in Table 5. In fermented sausages, the optimal colour formation strongly depends on the fermentation and the resulting $\mathrm{pH}$ decrease and oxygen depletion.

Table 5. Colour measurements of the Slavonian kulen samples after 20 days of fermentation

\begin{tabular}{cccc}
\hline Batch & $\mathrm{L}^{*}$ & $\mathrm{a}^{*}$ & $\mathrm{~b}^{*}$ \\
\hline B1 & $(47.23 \pm 0.07)^{\mathrm{e}}$ & $(15.5 \pm 0.1)^{\mathrm{c}}$ & $(22.62 \pm 0.08)^{\mathrm{b}}$ \\
B2 & $(50.2 \pm 0.2)^{\mathrm{b}}$ & $(17.1 \pm 0.2)^{\mathrm{b}}$ & $(22.9 \pm 0.2)^{\mathrm{b}}$ \\
B3 & $(50.66 \pm 0.03)^{\mathrm{a}}$ & $(18.6 \pm 0.1)^{\mathrm{a}}$ & $(21.90 \pm 0.06)^{\mathrm{c}}$ \\
B4 & $(49.1 \pm 0.1)^{\mathrm{c}}$ & $(17.28 \pm 0.08)^{\mathrm{b}}$ & $(23.4 \pm 0.1)^{\mathrm{a}}$ \\
B5 & $(48.8 \pm 0.1)^{\mathrm{d}}$ & $(17.47 \pm 0.07)^{\mathrm{b}}$ & $(22.08 \pm 0.08)^{\mathrm{c}}$ \\
\hline
\end{tabular}

Values are mean \pm S.D., $N=10$. Values in the same column marked with different letters in superscript are significantly different $(\mathrm{p}<0.05)$

The $L^{*}$ values were significantly modified after the addition of the autochthonous starter culture and sugar, as well as the change of fermentation temperature. The highest $L^{*}$ values were obtained of the batch B3 samples. Generally, samples fermented at higher temperature had higher L* values (Table 5). A higher L* value may be associated with lower $\mathrm{pH}$ values and consequently higher lactic acid concentrations established in these samples. In meat, higher lactic acid concentrations cause exudation once the meat proteins have reached their isoelectric point (41). The $a^{*}$ value was higher in the Slavonian kulen samples fermented at lower temperature. The decrease in $a^{*}$ value can only be associated with the effect of lactic acid on different myoglobin forms (myoglobin, nitrosomyoglobin and oxymyoglobin). This acid may partially or totally denaturise this compound. Some authors have reported that this acid decreases redness (41). The yellowness was altered markedly $(p<0.05)$ (Table 5$)$ by different fermentation temperatures and the addition of sugars and autochthonous starter culture. Higher fermentation temperature and the addition of autochthonous starter culture decreased yellowness $b^{*}$ value. This decrease could probably be attributed to the salt content (due to the effect of salt on oxygen solubility in the meat batter) 
(41), which was higher in samples fermented at higher temperature in the presence of glucose and maltodextrin and autochthonous starter culture (Table 4).

In view of the above, a more striking downfall of oxymyoglobin content, which greatly contributes to the value of this colour coordinate, is to be expected. Other authors have also claimed that microorganisms produce metabolites that induce oxidation of meat and fat present in the sausage (42) and, by doing so, contribute to the decrease in this value. Colour parameters measured after 20 days were similar to those of kulenova seka (whose stuffing and production process are virtually the same as for Slavonian kulen, the difference being that the stuffing is stuffed into the end part of the pig large intestine) and the Slavonian homemade sausage $(1,2)$.

The influence of autochthonous starter culture, glucose, maltodextrin and fermentation temperature on the instrumental texture profile (established after 20 days of fermentation) is shown in Table 6. The addition of autochthonous starter culture and sugars and variations in fermentation temperature significantly affected $(\mathrm{p}<0.05)$ hardness and chewiness. As expected, hardness and chewiness reached the highest values in batch B3 samples, followed by batch B5 samples, and were the lowest in batch B4 samples (fermented at $12{ }^{\circ} \mathrm{C}$ ). During fermentation, $\mathrm{pH}$ decreased and solubilised myofibrillar proteins aggregated to form a gel.

Therefore, the variability of texture across Slavonian kulen samples seen during fermentation could be explained by $\mathrm{pH}$ differences (Fig. 4).

The decrease in the $\mathrm{pH}$ gradually induces the aggregation of proteins, leading to the formation of an ordered protein network that contributes to firmness (43).

Table 6. Texture profile of the Slavonian kulen samples after 20 days of fermentation

\begin{tabular}{ccccc}
\hline Batch & $\frac{\text { Hardness }}{\mathrm{kg}}$ & Springiness & Cohesiveness & $\frac{\text { Chewiness }}{\mathrm{kg}}$ \\
\hline B1 & $(12.1 \pm 0.3)^{\mathrm{c}}$ & $(0.59 \pm 0.08)^{\mathrm{b}}$ & $(0.59 \pm 0.02)^{\mathrm{c}}$ & $(4.3 \pm 0.3)^{\mathrm{c}}$ \\
B2 & $(11.0 \pm 0.8)^{\mathrm{d}}$ & $(0.54 \pm 0.08)^{\mathrm{c}}$ & $(0.48 \pm 0.04)^{\mathrm{d}}$ & $(2.9 \pm 0.9)^{\mathrm{d}}$ \\
B3 & $(14.2 \pm 4.1)^{\mathrm{a}}$ & $(0.7 \pm 0.1)^{\mathrm{a}}$ & $(0.67 \pm 0.04)^{\mathrm{a}}$ & $(6.6 \pm 0.3)^{\mathrm{a}}$ \\
B4 & $(10.8 \pm 0.7)^{\mathrm{d}}$ & $(0.5 \pm 0.1)^{\mathrm{c}}$ & $(0.48 \pm 0.06)^{\mathrm{d}}$ & $(2.8 \pm 0.6)^{\mathrm{d}}$ \\
B5 & $(13.1 \pm 0.4)^{\mathrm{b}}$ & $(0.6 \pm 0.2)^{\mathrm{b}}$ & $(0.63 \pm 0.05)^{\mathrm{b}}$ & $(5.1 \pm 0.3)^{\mathrm{b}}$ \\
\hline
\end{tabular}

Values are mean \pm S.D., $N=7$. Values in the same column marked with different letters in superscript are significantly different $(p<0.05)$
In addition, acid solubilisation of collagen may occur (44). It has been demonstrated that if the $\mathrm{pH}$ falls below the isoelectric point of the muscle protein, solubilisation of the protein is higher producing firmer sausages (45). Our results are in agreement with the above mentioned, since only Slavonian kulen samples supplemented with autochthonous starter culture and $0.8 \%$ glucose and fermented at $20{ }^{\circ} \mathrm{C}$ had $\mathrm{pH}$ values below 4.5 during fermentation (Fig. 4). A major effect of autochthonous starter culture and sugar addition, and fermentation temperature on springiness and cohesiveness (Table 6) was detected after the end of fermentation.

Generally, batches fermented at higher temperature had higher texture parameter values than samples fermented at lower temperature, irrespective of autochthonous starter culture and sugar addition.

In the Slavonian kulen samples, Salmonella sp., Enterobacteriaceae, sulphite-reducing Clostridia and L. monocytogenes were not found (Table 7). Bacterial counts reached at the end of the Slavonian kulen fermentation are shown in Table 5. The highest counts of $1.2 \cdot 10^{7}$ of LAB and $9.6 \cdot 10^{3}$ $\mathrm{CFU} / \mathrm{g}$ of $\mathrm{CNS}$ were determined in batch B3 samples. In general, higher LAB and CNS counts were established in the samples fermented at higher temperature (Table 7).

The results of biochemical (API) testing of the Slavonian kulen samples (Table 8) showed that the dominant microflora in the samples supplemented with autochthonous starter culture was Lactobacillus plantarum, while in the control sample the predominant microflora was Lactobacillus sakei. In the samples without autochthonous starter culture, the most represented CNS strains were $S$. saprophyticus, S. equorum and S. warneri, while in the samples with the autochthonous starter culture the most represented CNS strain was proven to be $S$. curvatus (testing accuracy 99-99.9\%). The dominance of the above strains in the latter samples is to be expected since these strains are the components of the starter culture $(17,31,46)$.

Therefore, we can conclude that the applied autochthonous starter culture has better adapted to the meat environment and to the specific manufacturing process than the indigenous microbial population present in the control sample. In order to avoid possible misclassification, in addition to physiological (API) tests, the identification of the two applied bacterial species (an autochthonous starter culture) was confirmed using MALDI-TOF MS, which corroborated the presence of L. plantarum $1 \mathrm{~K}$ (data not shown) and S. carnosus $4 \mathrm{~K} 1$ (data not shown).

Table 7. Microbiological analysis of the Slavonian kulen samples after 20 days of fermentation

\begin{tabular}{lccccc}
\hline \multirow{2}{*}{ Species } & \multicolumn{3}{c}{ N(CFU/g) } \\
\cline { 2 - 6 } & Batch 1 & Batch 2 & Batch 3 & Batch 4 & Batch 5 \\
\hline Lactic acid bacteria & $6.5 \cdot 10^{6}$ & $5 \cdot 10^{5}$ & $1.2 \cdot 10^{7}$ & $8 \cdot 10^{5}$ & $1 \cdot 10^{7}$ \\
Enterobacteriacae & $1.2 \cdot 10^{2}$ & $<10^{2}$ & $<10^{2}$ & $<10^{2}$ & $<10^{2}$ \\
Salmonella sp. & N.D. & N.D. & N.D. & N.D. & N.D. \\
CNS (coagulase-negative staphylococci) & $1 \cdot 10^{2}$ & $1 \cdot 10^{2}$ & $9.6 \cdot 10^{3}$ & $1.2 \cdot 10^{3}$ & $5.1 \cdot 10^{3}$ \\
Sulphite-reducing clostridia & N.D. & N.D. & N.D. & N.D. & N.D. \\
Listeria moncytogenes & N.D. & N.D. & N.D. & N.D. & N.D. \\
\hline
\end{tabular}

N.D. $=$ not determined 
Table 8. Biochemical (API) test results for the Slavonian kulen samples obtained after 20 days of fermentation

\begin{tabular}{|c|c|c|c|c|}
\hline Batch & $\begin{array}{l}\text { Microorganism } \\
\text { type }\end{array}$ & $\begin{array}{c}N \\
\text { (colony) }\end{array}$ & API test & $\begin{array}{c}N \\
\text { (microorganism) }\end{array}$ \\
\hline \multirow{5}{*}{ B1 } & \multirow{2}{*}{ LAB } & \multirow{2}{*}{30} & L. sakei & 21 \\
\hline & & & L. plantarum & 9 \\
\hline & \multirow{3}{*}{ CNS } & \multirow{3}{*}{20} & S. saprophyticus & 5 \\
\hline & & & S. equorum & 6 \\
\hline & & & S. warneri & 9 \\
\hline \multirow{4}{*}{ B2 } & \multirow{2}{*}{ LAB } & \multirow{2}{*}{30} & L. plantarum & 23 \\
\hline & & & L. sakei & 7 \\
\hline & \multirow{2}{*}{ CNS } & \multirow{2}{*}{20} & S. carnosus & 14 \\
\hline & & & S. warneri & 6 \\
\hline \multirow{4}{*}{ B3 } & \multirow{2}{*}{ LAB } & \multirow{2}{*}{30} & L. plantarum & 26 \\
\hline & & & L. sakei & 4 \\
\hline & \multirow{2}{*}{ CNS } & \multirow{2}{*}{20} & S. carnosus & 15 \\
\hline & & & S. warneri & 5 \\
\hline \multirow{4}{*}{ B4 } & \multirow{2}{*}{ LAB } & \multirow{2}{*}{30} & L. plantarum & 26 \\
\hline & & & L. sakei & 4 \\
\hline & \multirow{2}{*}{ CNS } & \multirow{2}{*}{20} & S. carnosus & 13 \\
\hline & & & S. warneri & 7 \\
\hline \multirow{4}{*}{ B5 } & \multirow{2}{*}{ LAB } & \multirow{2}{*}{30} & L. plantarum & 28 \\
\hline & & & L. sakei & 2 \\
\hline & \multirow{2}{*}{ CNS } & \multirow{2}{*}{20} & S. carnosus & 15 \\
\hline & & & S. warneri & 5 \\
\hline
\end{tabular}

$\mathrm{LAB}=$ lactic acid bacteria, $\mathrm{CNS}=$ coagulase-negative staphylococci

A complex interaction among physicochemical, biochemical and microbiological processes, playing a role in the formation of chemical compounds, and the modification of molecules responsible for the texture and appearance of the final product, also determine its sensory characteristics. The average scores given by the panellists for all five batches at the end of the Slavonian kulen manufacturing process (90 days) are shown in Fig. 5. As for the external attributes, the highest hardness score was given to batch B3 samples $(4.4 \pm 0.7)$, while the appearance of the samples of all five batches was so similar that the assessors could not detect any differences among them. The slicing ability and colour intensity of batch B3 and B5 samples also scored highly.

Regarding the attributes that describe perceptions during mastication, batch B3 samples were highly rated for their flavour intensity $(4.4 \pm 0.2)$, juiciness $(3.8 \pm 0.2)$ and acidic taste (4.3 \pm 0.2$)$. Smokiness and saltines of all batches were assessed to be similar.

During the fermentation of dry sausages, LAB are known to produce lactic acid (47) responsible for the sour taste (48) and odour of the product, while a mouldy odour is ordinarily associated with 1-octen-3-ol, a typical component of mushroom odour (49). Batches fermented at higher temperature in the presence of glucose or maltodextrin and autochthonous starter culture (Fig. 5) had higher scores for all three attributes.

As for the smell, that of lactic acid was dominant, especially of the batches fermented at higher temperature

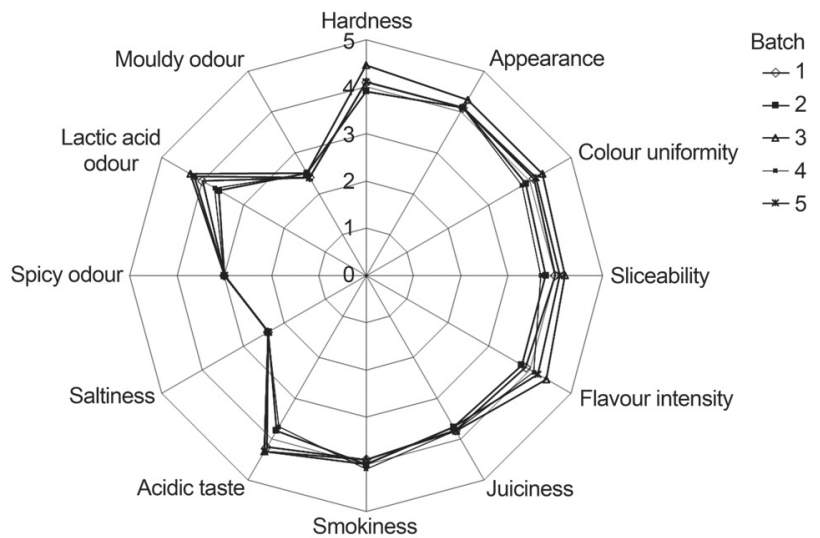

Fig. 5. Mean values of sensory properties of the Slavonian kulen samples determined after 90 days of production: batch 1: without sugar and with autochthonous starter culture, fermented at $20{ }^{\circ} \mathrm{C}$; batch 2 : with $0.8 \%$ glucose and autochthonous starter culture, fermented at $12{ }^{\circ} \mathrm{C}$; batch 3: with $0.8 \%$ glucose and autochthonous starter culture, fermented at $20{ }^{\circ} \mathrm{C}$; batch 4 : with $0.8 \%$ maltodextrin and autochthonous starter culture, fermented at $12{ }^{\circ} \mathrm{C}$; batch 5: with $0.8 \%$ maltodextrin and autochthonous starter culture, fermented at $20^{\circ} \mathrm{C}$

and supplemented with glucose or maltodextrin and autochthonous starter culture, while mouldy and spicy odour scored low in all five batches.

\section{Conclusion}

The addition of glucose, maltodextrin and autochthonous starter culture and using different fermentation temperatures $\left(12\right.$ and $20^{\circ} \mathrm{C}$ ) affected the Slavonian kulen fermentation. In conclusion, the batches fermented at higher temperature with added autochthonous starter culture had higher values of all textural parameters and $L^{*}$ and $a^{*}$ values, higher counts of lactic acid bacteria and coagulase-negative staphylococci, and lower moisture, $a_{\mathrm{w}}$ and $\mathrm{b}^{*}$ values regardless of sugar addition. Sensory analysis, undertaken at the end of the production process, proved higher fermentation temperature and autochthonous starter culture addition to have the greatest influence on the Slavonian kulen fermentation. Finally, it is important to emphasise that all of the investigated instrumental colour and texture parameters could be useful in monitoring the product evolution and, moreover, in an easy-to-perform control over the total duration of the Slavonian kulen fermentation and ripening.

\section{References}

1. Kovačević D, Mastanjević K, Šubarić D, Jerković I, Marijanović Z. Physico-chemical, colour and textural properties of Croatian traditional dry sausage (Slavonian kulen). Meso. 2010;12:270-6.

2. Kovačević D, Mastanjević K, Frece J, Pleadin J, Šakić I. Effect of addition of various sugars on fermentation process of Croatian indigenous dry sausage Kulenova seka. Meso. 2014; 16:351-5.

3. Pleadin J, Krešić G, Barbir T, Petrović M, Milinović I, Kovačević D. Changes in basic nutrition and fatty acid composition during production of 'Slavonski kulen'. Meso. 2014;16: 487-91 (in Croatian). 
4. Cocconcelli PS. Starter cultures. bacteria. In: Toldrá F, editor. Handbook of fermented meat and poultry. Oxford, UK: Blackwell Publishing; 2007. pp. 137-46. http://dx.doi.org/10.1002/9780470376430.ch13

5. Lizaso G, Chasco J, Beriain MJ. Microbiological and biochemical changes during ripening of salchichón, a Spanish dry cured sausage. Food Microbiol. 1999;16:219-28. http://dx.doi.org/10.1006/fmic.1998.0238

6. Villani F, Casaburi A, Pennacchia C, Filosa L, Russo F, Ercolini D. Microbial ecology of the soppressata of Vallo di Diano, a traditional dry fermented sausage from southern Italy, and in vitro and in situ selection of autochthonous starter cultures. Appl Environ Microbiol. 2007;73:5453-63. http://dx.doi.org/10.1128/AEM.01072-07

7. Casaburi A, Aristoy MC, Cavella S, Di Monaco R, Ercolini D, Toldrá F, Villani F. Biochemical and sensory characteristics of traditional fermented sausages of Vallo di Diano (Southern Italy) as affected by the use of starter cultures. Meat Sci. 2007;76:295-307.

http://dx.doi.org/10.1016/j.meatsci.2006.11.011

8. Varnam AH, Sutherland JP. Meat and meat products - technology, chemistry and microbiology. London, UK: Chapman \& Hall; 1995.

9. Toldrá F, Nip WK, Hui YH. Dry-fermented sausages: an overview. In: Toldrá F, editor. Handbook of fermented meat and poultry. Oxford, UK: Blackwell Publishing; 2007. pp. 321-5.

http://dx.doi.org/10.1002/9780470376430.ch30

10. Hammes WP, Knauf HJ. Starters in the processing of meat products. Meat Sci. 1994;36:155-68. http://dx.doi.org/10.1016/0309-1740(94)90039-6

11. Papamanoli E, Tzanetakis N, Litopoulou-Tzanetaki E, Kotzekidou P. Characterization of lactic acid bacteria isolated from a Greek dry-fermented sausage in respect of their technological and probiotic properties. Meat Sci. 2003;65:859-67. http://dx.doi.org/10.1016/S0309-1740(02)00292-9

12. Comi G, Urso R, Iacumin L, Rantsiou K, Cattaneo P, Cantoni C, Cocolin L. Characterisation of naturally fermented sausages produced in the North East of Italy. Meat Sci. 2005;69: 381-92.

http://dx.doi.org/10.1016/j.meatsci.2004.08.007

13. Lucke FK. Fermented meat products. Food Res Int. 1994;27: 299-307. http://dx.doi.org/10.1016/0963-9969(94)90098-1

14. Lücke FK. Utilization of microbes to process and preserve meat. Meat Sci. 2000;56:105-15. http://dx.doi.org/10.1016/S0309-1740(00)00029-2

15. Hüfner E, Britton RA, Roos S, Jonsson H, Hertel C. Global transcriptional response of Lactobacillus reuteri to the sourdough environment. Syst Appl Microbiol. 2008;31:323-38. http://dx.doi.org/10.1016/j.syapm.2008.06.005

16. Talon R, Leroy S, Lebert I, Giammarinaro P, Chacornac JP, Latorre-Moratalla $\mathrm{M}$, et al. Safety improvement and preservation of typical sensory qualities of traditional dry fermented sausages using autochthonous starter cultures. Int J Food Microbiol. 2008;126:227-34.

http://dx.doi.org/10.1016/j.ijfoodmicro.2008.05.031

17. Frece J, Kovačević D, Kazazić S, Mrvčić J, Vahčić N, Ježek D, et al. Comparison of sensory properties, shelf live and microbiological safety of industrial sausages produced with autochthonous and commercial starter cultures. Food Technol Biotechnol. 2014;52:307-16.

18. ISO 1442:1997. Meat and meat products - Determination of moisture content. Geneva, Switzerland: International Organization for Standardization (ISO); 1997.

19. ISO 937:1978. Meat and meat products - Determination of nitrogen content. Geneva, Switzerland: International Organization for Standardization (ISO); 1978.
20. ISO 1443:1973. Meat and meat products - Determination of total fat content. Geneva, Switzerland: International Organization for Standardization (ISO); 1973.

21. ISO 3496:1994. Meat and meat products - Determination of hydroxyproline content. Geneva, Switzerland: International Organization for Standardization (ISO); 1994.

22. Trajković J, Baras J, Mirić M, Šiler S. Analysis of foodstuff. Beograd, Yugoslavia: Tehnološko metalurški fakultet. Beograd; 1983 (in Serbian).

23. Bourne MC. Texture profile analysis. Food Technol. 1978;32: 62-6.

24. HRN EN ISO 6579:2003/A1:2008. Microbiology of food and animal feeding stuffs - Horizontal method for the detection of Salmonella spp. Zagreb, Croatia: The Croatian Standards Institute; 2008 (in Croatian).

25. HRN ISO 5552:1999. Meat and meat products - Detection and enumeration of Enterobacteriaceae without resuscitation - MPN technique and colony-count technique. Zagreb, Croatia: The Croatian Standards Institute; 1999 (in Croatian).

26. HRN EN ISO 6888-1:2004. Microbiology of food and animal feeding stuffs - Horizontal method for the enumeration of coagulase-positive staphyloccoco (Staphylococcus aureus and other species) - Part 1: Technique using Baird-Parker agar medium (ISO 6888-1:1999+Amd 1:2003; EN ISO 68881:1999+A1:2003). Zagreb, Croatia: The Croatian Standards Institute; 2004 (in Croatian).

27. HRN ISO 15213:2004. Microbiology of food and animal feeding stuffs - Horizontal method for the enumeration of sulfite-reducing bacteria growing under anaerobic conditions. Zagreb, Croatia: The Croatian Standards Institute; 2004 (in Croatian).

28. HRN EN ISO 11290-1:1999/A1:2008. Microbiology of food and animal feeding stuffs - Horizontal method for the detection and enumeration of Listeria monocytogenes - Part 1: Detection method - Amendment 1: Modification of the isolation media and the haemolysis test, and inclusion of precision data (ISO 11290-1:1996/Amd 1:2004; EN ISO 112901:1996/A1:2004). Zagreb, Croatia: The Croatian Standards Institute; 2008 (in Croatian).

29. HRN ISO 13721:1999. Meat and meat products - Enumeration of lactic acid bacteria - Colony-count technique at 30 degrees C (ISO 13721:1995). Zagreb, Croatia: The Croatian Standards Institute; 1999 (in Croatian).

30. Regulation on Food Hygiene and Microbiological Criteria for Food No. 18/13. Zagreb, Croatia: Official Gazette of the Republic of Croatia; 2013 (in Croatian).

31. Babić I, Markov K, Kovačević D, Trontel A, Slavica A, Đugum J, et al. Identification and characterization of potential autochthonous starter cultures from a Croatian 'brand' product 'Slavonski kulen'. Meat Sci. 2011;88:517-24. http://dx.doi.org/10.1016/j.meatsci.2011.02.003

32. ISO 8586:2012. Sensory analysis - General guidelines for the selection, training and monitoring of selected assessors and expert sensory assessors. Geneva, Switzerland: International Organization for Standardization (ISO); 2012.

33. Benito MJ, Rodríguez M, Martín A, Aranda E, Córdoba JJ. Effect of the fungal protease EPg222 on the sensory characteristics of dry fermented sausage 'salchichón' ripened with commercial starter cultures. Meat Sci. 2004;67:497-505. http://dx.doi.org/10.1016/j.meatsci.2003.11.023

34. González-Fernández C, Santos EM, Rovira J, Jaime I. The effect of sugar concentration and starter culture on instrumental and sensory textural properties of chorizo-Spanish dry-cured sausage. Meat Sci. 2006;74:467-75. http://dx.doi.org/10.1016/j.meatsci.2006.04.019

35. Ockerman HW, Basu L. Production and consumption of fermented meat products. In: Toldrá F, editor. Handbook of fer- 
mented meat and poultry. Oxford, UK: Blackwell Publishing; 2007. pp. 9-15. http://dx.doi.org/10.1002/9780470376430.ch2

36. Hagen BF, Næs, H, Holck AL. Meat starters have individual requirements for $\mathrm{Mn}^{2+}$. Meat Sci. 2000;55:161-8. http://dx.doi.org/10.1016/S0309-1740(99)00138-2

37. Salgado A, García Fontán MC, Franco I, López M, Carballo J. Biochemical changes during the ripening of chorizo de cebolla, a Spanish traditional sausage. Effect of the system of manufacture (homemade or industrial). Food Chem. 2005;92: 413-24. http://dx.doi.org/10.1016/j.foodchem.2004.07.032

38. Revilla I, Vivar Quintana AM. The effect of different paprika types on the ripening process and quality of dry sausages. Int J Food Sci Tech. 2005;40:411-7. http://dx.doi.org/10.1111/j.1365-2621.2005.00944.x

39. Montel MC, Talon R, Berdagué JL, Cantonnet M. Effects of starter cultures on the biochemical characteristics of French dry sausages. Meat Sci. 1993;35:229-40. http://dx.doi.org/10.1016/0309-1740(93)90053-K

40. Stahknke LH, Tjener K. Influence of processing parameters on cultures performance. In: Toldrá $\mathrm{F}$, editor. Handbook of fermented meat and poultry. Oxford, UK: Blackwell Publishing; 2007. pp.187-94. http://dx.doi.org/10.1002/9780470376430.ch18

41. Perez-Alvarez JA, Sanchez-Rodríguez E, Fernandez-Lopez J, Gago-Gago MA, Ruíz-Peluffo C, Rosini M, et al. Chemical and color characteristics of 'Lomo embuchado' during salting seasoning. J Muscle Foods. 1997;8:395-411. http://dx.doi.org/10.1111/j.1745-4573.1997.tb00728.x
42. Demeyer DI, Verplaetse A, Gistelinck M. Fermentation of meat: an integrated process. Belg J Chem Biotechnol. 1986;41:131-9.

43. Fretheim K, Egelandsdal B, Harbitz O, Samejima K. Slow lowering of $\mathrm{pH}$ induces gel formation of myosin. Food Chem. 1985;18:169-78. http://dx.doi.org/10.1016/0308-8146(85)90044-5

44. Aktaş N, Kaya M. Influence of weak organic acids and salts on the denaturation characteristics of intramuscular connective tissue. A differential scanning calorimetry study. Meat Sci. 2001;58:413-9. http://dx.doi.org/10.1016/S0309-1740(01)00044-4

45. Matulis RJ, McKeith FK, Sutherland JW, Brewer MS. Sensory characteristics of frankfurters as affected by fat, salt, and $\mathrm{pH}$. J Food Sci. 1995;60:42-7. http://dx.doi.org/10.1111/j.1365-2621.1995.tb05603.x

46. Frece J, Markov K, Kovačević D. Determination of indigenous microbial populations, mycotoxins and characterization of potential starter cultures in Slavonian kulen. Meso. 2010;12:92-9 (in Croatian).

47. Mateo J, Domínguez MC, Aguirrezábal MM, Zumalacárregui JM. Taste compounds in chorizo and their changes during ripening. Meat Sci. 1996;44:245-54. http://dx.doi.org/10.1016/S0309-1740(96)00098-8

48. Lotong V, Chambers IVE, Chambers DH. Determination of the sensory attributes of wheat sourdough bread. J Sens Stud. 2000;15:309-26. http://dx.doi.org/10.1111/j.1745-459X.2000.tb00273.x

49. Meynier A, Genot C, Gandemer G. Volatile compounds of oxidized pork phospholipids. J Am Oil Chem Soc. 1998;75: 1-7. http://dx.doi.org/10.1007/s11746-998-0001-3 